\title{
O INDIVÍDUO IDOSO E O CAIXA ELETRÔNICO: UM ESTUDO COM O USUÁRIO FEMININO
}

\author{
Milena Viana da Silva \\ Universidade Federal do Maranhão \\ milenawm1@gmail.com \\ Lívia Flávia de Albuquerque Campos \\ Universidade Federal do Maranhão \\ livia.albuquerque@ufma.br \\ Andre Leonardo Demaison \\ Universidade Federal do Maranhão \\ demaison@gmail.com
}

Resumo: O presente artigo aborda o levantamento de itens preliminares para uma proposta de interface considerando o usuário feminino idoso. 0 número de idosos está crescendo em todo o mundo e há um aumento maior em relação ao sexo feminino, concentrado principalmente em áreas urbanas e que contribuem com o rendimento familiar (IBGE, 2013). O método norteador deste trabalho envolve as fases iniciais do Design Participativo: Exploração Inicial e Fase de Descoberta. Foram realizadas análises através da aplicação de workshops e grupo focal, a fim de se obter informações a respeito de características e necessidades desses usuários. 0 resultado foi o desenvolvimento de itens preliminares para a interface que considere as necessidades e capacidades desses indivíduos.

Palavras-chave: Usabilidade; Design participativo; Interface.

Abstract: This article discusses the survey of preliminary items for a proposed interface considering the female elderly user. The number of elderly is growing worldwide and there is a greater increase compared to females, mainly concentrated in urban areas and contributing to the family income (IBGE, 2013). The guiding method of this work involves the early stages of Participatory Design: Initial Exploration and Discovery Phase. Analyses were performed by applying workshops, focus group in order to obtain information about the characteristics and needs of these users. The result was the development of preliminary items for the interface that considers the needs and capabilities of these individuals.

Keywords: Usability; Participatory design; Interface. 


\section{INTRODUÇÃO}

Na década de 60, houve o início no Brasil a automação bancária. Com isto, os processos bancários passaram a ter mais agilidade e consequentemente aumentaram os produtos e serviços prestados. Toda essa evolução fez com que as instituições bancárias buscassem novas tecnologias para melhorar o atendimento (DRESCH, 2012).

Os caixas eletrônicos são máquinas que oferecem produtos e serviços bancários 24 sem a necessidade de manipulação por terceiros. Por causa dessas características, as instituições bancárias oferecem através deste sistema, o maior número de serviços possíveis, visto à conveniência e rapidez que estes dispositivos oferecem aos consumidores (DRESCH, 2012).

Goldman (2007, apud RAYMUNDO, 2013) cita que a expansão de produtos tecnológicos solicita aos usuários cada vez mais conhecimentos e agilidade ao executar tarefas. Essa habilidade é empregada na utilização de vários dispositivos do dia a dia, como telefones, internet, entre outros. Todavia, nem todos os usuários possuem estas habilidades da mesma forma.

Schiffmann \& Kanuk (2000, apud DRESCH, 2012), classificou seis tipos de riscos que consumidores possam ter em relação às transações bancárias:

- Risco funcional: onde o produto ou serviço não apresente o desempenho esperado;

- Risco físico: o risco para si próprio ou para os outros que o produto possa impor

- Risco financeiro: onde o produto não valha o custo;

- Risco social: quando uma escolha errada gera constrangimento;

- Risco psicológico: quando uma escolha errada interfere o ego do consumidor

- Risco de tempo: quando o tempo gasto na procura do serviço passa a ser visto como desperdício de tempo.

Neste cenário, os usuários idosos não tem acompanhado totalmente este processo. Em seus estudos, Raymundo (2013) concluiu que um grande número de idosos tem medo de usar diversos dispositivos tecnológicos. As mulheres apresentam mais atitudes negativas se comparadas aos homens, pois estes são culturalmente associados à tecnologia em tarefas como pagamento de contas, ser o chefe de casa, etc.

O número de idosos tem aumentado consideravelmente no decorrer dos anos e a busca pelo uso de novas tecnologias por esses usuários, também. $O$ barateamento das tecnologias e programas de inclusão digital tem feito com que a população tenha acesso a novas tecnologias (KASHAR, 2010). Para ela, a geração adulta e velha não tem a mesma facilidade de manuseio com os artefatos tecnológicos como a geração mais nova, pois estes já exploram desde cedo diversos brinquedos tecnológicos.

As características dos idosos brasileiros são presença em área urbana $(84,1 \%)$, maioria branca $(55,0 \%)$ e inserção no domicílio como a pessoa de referência $(63,7 \%)$ (IBGE, 2013). Os números do IBGE mostram ainda, que a principal fonte de rendimento dos idosos de 60 anos ou mais foi a aposentadoria ou a pensão, equivalendo a $66,2 \%$, e chegando a $74,7 \%$ no caso do grupo de 65 anos ou mais. Houve ainda um aumento 
de $40 \%$ de idosos e deficientes de baixa renda que passaram a receber do governo 0 Beneficio de Prestação Continuada, o que equivale a cerca de 966.300 idosos incluídos no programa.

Outra informação importante é a feminização da velhice, que apresenta percentual crescente, conforme o avanço da idade (Secretaria de Direitos Humanos, Brasil). Para Camarano (2004) existe uma predominância de mulheres conforme o avanço da idade. E este percentual aumenta nas áreas urbanas, pois a mulher tem mais probabilidade de ficar viúva e se tornar provedora do lar. A maior expectativa de vida das mulheres é resultado de sua maior preocupação em relação à assistência médica, apoio social e menor vulnerabilidade biológica. Outro fator são os problemas de saúde, que em mulheres costumam ser de longo prazo, enquanto que os homens são mais acometidos por doenças de curto prazo e fatais (PARENTE, 2009).

A norma ABNT NBR 15250 (2005) foi criada com o objetivo de estabelecer parâmetros para o projeto acessível de caixas eletrônicos, considerando o design universal, ou seja, o maior número possível de pessoas, independentemente de características secundárias. Entretanto, na relação de indivíduos idosos com os caixas eletrônicos, vários estudos observaram que ainda há barreiras que impedem os usuários idosos de usufruírem todos os benefícios da tecnologia (BORIN et al 2009; SANTOS E CARVALHO, 2013; PITERRI et al 2010; MAZZONI E TORRES, 2008; NETO et al 2002). Muitos se limitam a aprender somente o básico, como o saque.

Estudos realizados com usuários idosos apontam que a operação mais comum realizada em postos de autoatendimento é o saque com percentual de $73 \%$. Além disso, $75 \%$ dos usuários gostariam que fosse implementado caixas especiais para idosos (SANTOS e CARVALHO, 2013). Foi constatado ainda que a maioria dos entrevistados se sentem nervosos ao utilizar o caixa de autoatendimento e pedem colaboração de funcionários da agência para realizarem a tarefa. Neste sentido, a ergonomia e usabilidade tem o papel de adaptar a interface às necessidades da pessoa idosa.

Vê-se, portanto, a importância de se tornarem conhecidos os requisitos para uma proposta de interface que contribua para a independência do idoso ao usar os serviços dos caixas eletrônicos. O Design Participativo posiciona-se como ferramenta vital para este processo. Assim, o objetivo deste estudo é compreender as necessidades dos idosos com relação ao caixa eletrônico, a fim de, elaborar uma lista preliminar de itens para uma proposta de interface interativa segura, eficiente, eficaz e agradável.

\section{A USABILIDADE DE INTERFACES}

A norma ISO 9241-11, propõe a seguinte definição de usabilidade: "...efetividade, eficiência e satisfação com a qual usuários específicos alcançam metas especificadas em ambientes particulares - efetivamente, eficientemente, confortavelmente e de modo aceitável." Stanton \& Barber (1992, apud MORAES; FRISONI 2001), apresentam um resumo de trabalhos representados por Shackel, Eason e Booth, onde sugerem os fatores que determinam o conceito de usabilidade, tais como:

- Facilidade de aprendizagem - onde o usuário alcança um desempenho 
aceitável dentro de um tempo estipulado.

- Efetividade no desempenho - onde uma parcela definida da população de usuários, possa alcançar níveis de desempenho aceitáveis, em relação à variação de tarefas e ambientes.

- Atitude - um desempenho aceitável deve ser atingido considerando custos humanos aceitáveis, em termos de fadiga, stress, frustração, desconforto e satisfação.

- Flexibilidade - o produto deve ser capaz de realizar uma variação de tarefas além das que foram especificadas inicialmente.

- Utilidade do produto - conferir a um produto, critérios como aprendizagem, efetividade, atitude e flexibilidade que indiquem a usabilidade.

- Adequação das tarefas, em relação às funções presentes no sistema, e as necessidades do usuário - as tarefas relacionadas ao produto devem adequar-se as necessidades do usuário.

- Características da tarefa - a frequência com que uma tarefa pode ser desempenhada e o grau no qual a tarefa pode ser modificada, em temos de variabilidade dos requisitos de informação.

- Características do usuário - as características dos usuários, como conhecimento, habilidade e motivação.

Moraes e Frisoni (2001) mostram que, constantemente, a preocupação com a usabilidade só ocorre nas etapas de conclusão do projeto. Esta atitude causa poucas modificações posteriores de correção do projeto, por significarem custos elevados. Deste modo, deve-se dar a devida importância as fases iniciais de planejamento do projeto. Para lida (2005), no projeto participativo, os usuários fazem avaliações em todas as etapas, com a finalidade de corrigir os erros.

NIELSEN (1994) propôs um conjunto com dez qualidades intituladas de Heurísticas da Usabilidade, que são usadas como base para o desenvolvimento de qualquer interface:

- Visibilidade do status do sistema: O sistema deve sempre manter os usuários informados sobre o que está acontecendo e fornecer um feedback adequado, dentro de um tempo razoável.

- Compatibilidade do sistema com mundo real: O sistema deve falar a língua do usuário com palavras e conceitos familiares a este, em vez de termos voltados para 0 sistema.

- Controle do usuário e liberdade: Os usuários frequentemente escolhem funções do sistema por engano e precisarão de uma "saída de emergência", visivelmente identificada, para deixar aquela situação indesejável sem ter que passar por um extenso diálogo.

- Consistência e padrões: Usuários não devem temer que diferentes palavras, situações ou ações signifiquem a mesma coisa.

- Prevenção de erros: Deve ser um projeto cuidadoso, que evita a sua ocorrência, melhor do que boas mensagens de erro.

- Reconhecimento em vez de memorização: Minimizar a sobrecarga da memória do usuário, ao tornar visíveis os objetos, ações e opções.

- Flexibilidade e eficiência de uso: Teclas ou outros recursos de atalhos podem acelerar a interação do usuário experiente com o sistema.

- Estética e design minimalista: Os diálogos não devem conter informações 
irrelevantes.

- Ajudar o usuário a reconhecer, diagnosticar e corrigir erros: As mensagens de erro devem ser redigidas numa linguagem clara, não codificada, indicar o problema e sugerir uma solução.

- Ajuda e documentação: Qualquer informação deve ser fácil de buscar, focalizada na tarefa do usuário, além de listar passos concretos a serem executados e não ser muito grande.

\section{MÉTODOS E TÉCNICAS}

O presente estudo é do tipo descritivo. A qual, segundo Lakatos (2003), aborda quatro aspectos: investigação, registro, análise e interpretação de fenômenos atuais, objetivando o seu funcionamento no presente. Por envolver procedimentos com seres humanos e a necessidade de adequação aos critérios éticos, esta pesquisa foi submetida ao Comitê de Ética em Pesquisa da UFMA.

Além disso, todos os voluntários leram e assinaram o Termo de Consentimento Livre e Esclarecido (TCLE). Participaram desta pesquisa 30 indivíduos idosos do gênero feminino, os quais são definidos, de acordo com o Estatuto do idoso (BRASIL, 2004), como indivíduos com idade superior ou igual a 60 anos.

\subsection{Etapas do design participativo}

Para esta pesquisa utilizou-se como base a metodologia do Design Participativo (MORAES; SANTA ROSA, 2012). Seu objeto de estudo, é o conhecimento tácito desenvolvido por quem participa. Neste método, os usuários participam do projeto, como se fizessem parte da equipe que o desenvolve (MORAES; SANTA ROSA, 2012). Spinuzzi (2005, apud MORAES; SANTA ROSA, 2012), apresenta três estágios básicos na pesquisa do design participativo: Exploração inicial do trabalho, processo de descoberta e prototipação, no entanto, nesta pesquisa serão realizadas somente as duas primeiras etapas.

A Exploração inicial do trabalho se dá pela familiarização do pesquisador e dos participantes, ambientes e ferramentas de trabalho. Por fazer parte do início da pesquisa, nesta fase, os pesquisadores organizam workshops, onde eles discutem questões relativas ao projeto (MORAES; SANTA ROSA, 2012). O formato de workshop mais conhecido é a "Oficina do Futuro" (KENSING; MADSEN, 1992, apud MORAES; SANTA ROSA, 2012), que divide as atividades em três fases: (1) Críticas à situação atual; (2) Previsão de cenários futuros; (3) Transição do cenário atual para o futuro.

O workshop foi realizado na Universidade da Terceira Idade UNITI - UFMA. Teve duração de 45 minutos e contou com 15 pessoas com idade média de 65,46 anos do gênero feminino. Inicialmente, foi explicado às participantes o objetivo do projeto. Logo após foi feita uma explicação do TCLE (Termo de Consentimento Livre e Esclarecido). Todas as participantes presentes aceitaram participar da pesquisa. Para fins de registro da técnica realizada, foi solicitado às participantes permissão para que a reunião fosse registrada por meio de fotos, não havendo oposição.

Em seguida foram explicados, também, de forma simplificada, os conceitos básicos de Design, Ergonomia, Ergodesign, Design Participativo e a contribuição destes para o projeto de interfaces. Foram apresentados alguns exemplos de produtos 
cotidianos, que por conterem erros de usabilidade, causam algum tipo de problema aos usuários. A partir destes exemplos práticos, foram solicitadas as impressões e opiniões das participantes sobre produtos que causam desconforto na utilização. Logo após, foram discutidas mais detalhadamente as questões vistas, como problema no caixa eletrônico e itens que podem ser melhorados neste (Figura 1).

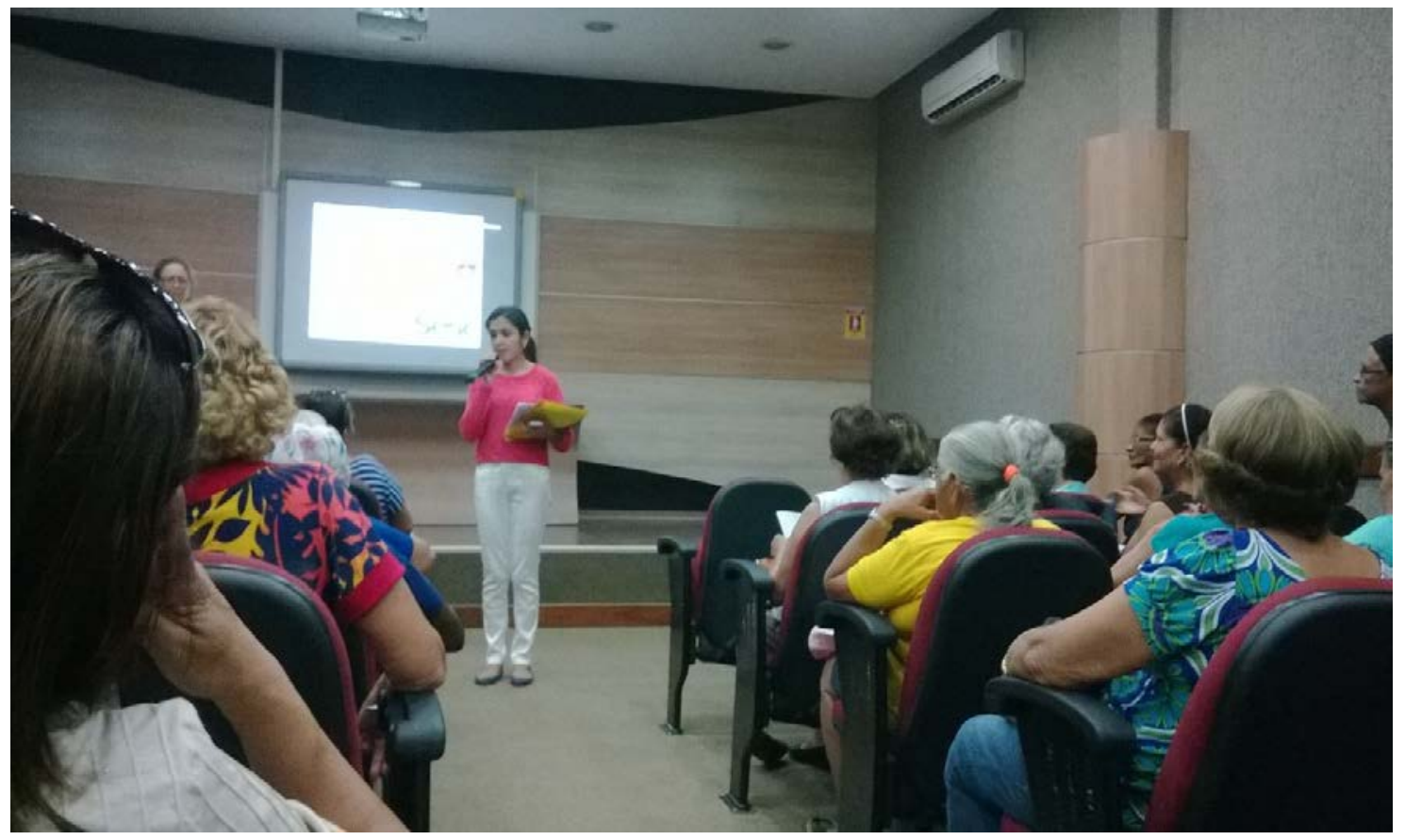

Figura 1 - Workshop realizado com as participantes.

Fonte: Elaborado pelos autores

Após uma semana ocorreu Processo de descoberta. Neste momento, designers e usuários utilizam várias técnicas para compreender a organização do trabalho (MORAES; SANTA ROSA, 2012).

Para esta pesquisa, a técnica escolhida foi o grupo focal, que é uma técnica de reunião onde o pesquisador faz questionamentos aos participantes para que eles se expressem em relação a um produto ou serviço. Nesta técnica não existem respostas erradas, todos os sentimentos e impressões dos usuários são importantes para o desenvolvimento do projeto (MORAES; SANTA ROSA, 2012). O grupo focal teve duração de 40 minutos e contou com 15 participantes.

Para a elaboração das perguntas do roteiro, foram revistas todas as opiniões relatadas durante o Workshop e a partir daí as perguntas giraram em torno dos tópicos relativos a Desconfortos gerais do caixa eletrônico; Segurança e Interface. Para cada pergunta feita às participantes, foi solicitado falar o que as incomodava e qual a forma para solucionar esses problemas.

As perguntas formuladas com base nos resultados do Workshop estão descritas abaixo (Tabela 1). 
Tabela 1 - Perguntas para o grupo focal.

\begin{tabular}{|c|c|c|}
\hline Características Gerais & Segurança & Interface \\
\hline $\begin{array}{l}\text { 1. Quais são os maiores } \\
\text { incômodos ao utilizar o caixa } \\
\text { eletrônico? }\end{array}$ & $\begin{array}{l}\text { 1. Qual a solução para } \\
\text { a fila? }\end{array}$ & $\begin{array}{l}\text { 1. Na tela do caixa eletrônico, você } \\
\text { encontra facilmente a opção } \\
\text { desejada? }\end{array}$ \\
\hline $\begin{array}{l}\text { 2. Quando surge alguma dúvida, } \\
\text { qual sua reação? }\end{array}$ & $\begin{array}{l}\text { 2. Com que } \\
\text { frequência você pede } \\
\text { ajuda a um } \\
\text { funcionário da } \\
\text { agência? }\end{array}$ & $\begin{array}{l}\text { 2. O tamanho das letras causa } \\
\text { dificuldade de visualização? }\end{array}$ \\
\hline $\begin{array}{l}\text { 3. Para você, qual operação é } \\
\text { considerada mais fácil? }\end{array}$ & $\begin{array}{l}\text { 3. Você costuma ir à } \\
\text { agência sozinha ou } \\
\text { acompanhada? }\end{array}$ & $\begin{array}{l}\text { 3. As cores presentes na tela do } \\
\text { caixa eletrônico causam algum tipo } \\
\text { de interferência? }\end{array}$ \\
\hline $\begin{array}{l}\text { 4. Entre caixa convencional e caixa } \\
\text { eletrônico, qual você prefere e } \\
\text { por quê? }\end{array}$ & & $\begin{array}{l}\text { 4. As palavras utilizadas no caixa } \\
\text { eletrônico são de fácil } \\
\text { entendimento? }\end{array}$ \\
\hline $\begin{array}{l}\text { 5. Você tem alguma dificuldade } \\
\text { em memorizar as senhas? } \\
\text { (numéricas e combinação de } \\
\text { letras) }\end{array}$ & & $\begin{array}{l}\text { 5. Você consegue associar as teclas } \\
\text { de seleção às opções disponíveis na } \\
\text { tela? }\end{array}$ \\
\hline $\begin{array}{l}\text { 6. Seu banco utiliza o } \\
\text { reconhecimento biométrico? Qual } \\
\text { sua opinião? }\end{array}$ & & $\begin{array}{l}\text { 6. No menu, você consegue localizar } \\
\text { facilmente a opção desejada? }\end{array}$ \\
\hline \multirow[t]{2}{*}{$\begin{array}{l}\text { 7.Você acha que as etapas } \\
\text { poderiam ser diminuídas? De que } \\
\text { maneira? }\end{array}$} & & $\begin{array}{l}\text { 7. Você consegue completar a tarefa } \\
\text { em um curto prazo? }\end{array}$ \\
\hline & & $\begin{array}{l}\text { 8. A falta de padrão de operação } \\
\text { entre as instituições bancárias causa } \\
\text { algum prejuízo aos usuários? }\end{array}$ \\
\hline
\end{tabular}

Fonte: Elaborado pelos autores

\section{RESULTADOS}

\subsection{Workshop}

Dentre as participantes $73 \%$ fazem uso de algum caixa eletrônico, enquanto que $27 \%$ responderam que não utilizam.

Quanto às críticas com relação à situação atual as participantes relataram desconfortos em relação ao espaço físico, onde a proximidade das pessoas que estão na fila com as demais que estão utilizando os caixas eletrônicos causa desconfiança de que algum dado pessoal possa ser identificado e subtraído na aplicação de golpes.

Outro fator que gera insegurança é em relação aos funcionários da agência, onde foi relatado que estes não ficam em tempo integral nas agências e não estão em outros locais que possuem terminais de caixas eletrônicos, como shoppings e supermercados.

O tamanho das letras, em geral, foi motivo de reclamação apenas por parte das 
usuárias que relataram ter alguma dificuldade relacionada à visão. Nesses casos, foi relatado também que o nível de brilho muito alto podem causar prejuízo na visualização da tela.

Outro fator que teve alto índice de reprovação por parte das usuárias foi o pouco tempo entre as etapas, que em caso de demora, cancela a operação fazendo com que o usuário tenha que repetir todos os procedimentos, e quando alguma informação errada é inserida, também existe e necessidade de repetir a operação. Isso causa desconforto nas usuárias, pois em caso de sucessivos erros ou repetições, o cartão pode ser bloqueado.

A existência de abreviaturas ou códigos desconhecidos intimidam os usuários, pois estes temem que possa se tratar de alguma operação que necessite de pagamentos de tarifas.

Já a previsão de cenários futuros incluíram propostas que visem a simplicidade da interface de acordo com suas necessidades. Dentre elas, foi proposto que as funções mais utilizadas ficassem em lugares mais visíveis da tela, a diminuição das etapas e o uso de palavras de fácil entendimento.

Foi sugerido também, assim como em bancos que possuem atendimento especial, que fossem criados caixas exclusivos para atendimento de idosos, com a interface voltada para pessoas desta faixa etária.

Algumas usuárias informaram que a biometria em alguns casos, embora apresentasse demora na identificação da digital, ainda é a alternativa mais fácil, pois torna a operação mais segura, dispensa o uso de senhas e acelera o processo.

\subsection{Grupo focal}

Quanto às características gerais os pontos relatados foram:

- Precisar de ajuda de algum funcionário e nem sempre encontrar;

- Quando surge alguma dúvida que a usuária não consegue resolver, geralmente ele procura por um funcionário da agência;

- A opção saldo é considerada mais simples de todas, pois envolve menos etapas e solicitação de senhas;

- Os caixas eletrônicos só estão na preferência das usuárias quando elas tem conhecimento da operação que vão realizar. Opções mais detalhadas e/ou complexas geralmente são realizadas diretamente com um atendente, pois este pode solucionar algum eventual problema. Outro agravante é que sucessivas tentativas erradas em uma operação podem fazer com que o cartão seja bloqueado.

- Senhas numéricas foram as mais bem aceitas. As usuárias reclamaram que a combinação de letras e palavras chave é mais difícil para memorização. Exemplo: ano de nascimento do pai.

- As usuárias que possuem contas em bancos realizam o reconhecimento biométrico acham essa opção mais vantajosa, pois evita o uso de senhas e diminui a quantidade de etapas, no entanto, argumentaram que às vezes, o processo de reconhecimento biométrico demora ou falha.

- O problema das etapas muito longas pode ser resolvido com as principais operações sendo colocadas na tela inicial e com a utilização de senhas mais fáceis de 
memorização.

Quanto aos aspectos de segurança, os pontos ressaltados foram:

- Para que as usuárias se sintam mais confortáveis, seria ideal a colocação de uma divisória que separasse a pessoa que está utilizando o caixa eletrônico, das demais que estão aguardando na fila.

- Usuárias que não usam o caixa eletrônico geralmente vão acompanhadas de alguém de confiança, ou quando vão sozinhas pedem ajuda a um funcionário.

- Usuárias mais experientes realizam as tarefas sozinhas, mas quando surge alguma dúvida, procuram algum funcionário, pois temem que o erro possa causar algum tipo de prejuízo. Exemplo: bloqueio do cartão, cobrança extra de tarifas, etc.

Quanto às interfaces dos caixas eletrônicos, relatou-se:

- As operações principais são encontradas com facilidade, mas uma operação não comum para o usuário pode causar confusão.

- Usuárias com problemas visuais afirmaram gastar mais tempo para visualizar a informação, mesmo sendo uma usuária experiente.

- Somente cores "muito fortes" foram alvo de reclamação das usuárias.

- A reclamação com relação às palavras se dá pelo uso de abreviaturas e palavras em outro idioma.

- As usuárias mais experientes conseguem associar a tecla às opções disponíveis na tela. Já usuárias inexperientes possuem dificuldade em identificar a opção correta.

- Geralmente as usuárias leem todas as informações na tela, e devido ao tempo gasto, eventualmente a tarefa é anulada sem que o usuário tenha completado as etapas.

\subsection{Requisitos preliminares para interfaces de caixas eletrônicos}

Com base nas observações dos indivíduos idosos do gênero feminino e na literatura de usabilidade considera-se relevante observar os seguintes aspectos:

- Telas devem ser simplificadas e apresentar somente informações claras e pertinentes à tarefa e evitando informações desnecessárias;

- As etapas devem ser minimizadas a fim de reduzir a carga de trabalho;

- A disposição de operações apresentadas na interface deve facilitar a decisão do usuário e ser classificadas de acordo com a frequência de uso, pois como observado, as operações mais comuns realizadas pelos usuários são o saque e a consulta de saldo;

- Oferecer controle do usuário em relação às opções, oferecendo em todas as etapas, as opções para corrigir, voltar, refazer ou anular;

- Oferecer tempo de etapas e entrada de dados maior, respeitando as necessidades do usuário, pois como constatado, os usuários idosos precisam de mais tempo para visualizar a informação, entender, tomar a decisão, localizar e acionar o comando desejado e as interfaces atuais apresenta um tempo mais curto para essa entrada de dados, que muitas vezes faz com que operação seja cancelada automaticamente, obrigando o usuário a ter que repetir o processo;

- Deve apresentar contraste adequado, principalmente para informações mais relevantes. 
- O uso de formas, cores e símbolos permitem que o usuário reconheça as etapas sem a necessidade de memorizar.

- O sistema só deve realizar as solicitações que forem solicitadas pelos usuários.

- O sistema deve respeitar os níveis de experiência do usuário. Deste modo, devem existir informações de ajuda para usuários iniciantes e atalhos para os mais experientes.

- Como relatado na pesquisa, o reconhecimento biométrico é mais eficiente para usuários idosos, pois dispensa a memorização de senhas, no entanto, nem todas as instituições bancárias apresentam esta opção, por isso, em relação às senhas, o ideal é criar um padrão para o número de dígitos entre as instituições bancárias, visto que senhas mais curtas são mais fáceis de serem lembradas. Quanto às senhas alfabéticas (combinação de sílabas), é aconselhável que sejam criadas estratégias de memorização no momento da geração das senhas.

- Como forma de minimizar as etapas de operação, é aconselhável que no campo para selecionar um valor para saque, as opções pré-definidas e campo para digitar um valor específico sejam apresentadas na mesma tela, ou que seja apresentada somente a opção de inserir o valor desejado.

- As opções para período de extrato devem ser padronizadas de forma que sejam apresentadas somente as quem são solicitadas com mais frequência.

- As opções que necessitem de inserção de cartão, envelopes, saída de comprovantes ou dinheiro devem ser acompanhadas de ilustrações que indiquem como proceder e informando a localização do mesmo.

- Ícones devem ser simples, evitando o excesso de cores e devem ser usados apenas para informações mais básicas. Exemplo: tela ou menu inicial, encerrar ou finalizar, etc.

- Com o propósito de diminuir o número de etapas envolvidas nas operações, é aconselhável que as duas senhas (numérica e alfabética) sejam solicitadas apenas na operação de saque. Nas operações de saldo e extrato pode ser solicitada apenas a senha numérica;

- É aconselhável que as operações apresentem no fim da tarefa outras sugestões de operações, a fim de que sejam evitadas repetições das tarefas. Exemplo: ao final da consulta de saldo, seja apresentada a opção de saque ou extrato.

- Deve-se garantir um bom contraste entre letras e fundo;

- A mensagem deve ser apresentada na língua do usuário (língua vernácula, ou seja, o idioma de origem do usuário) e evitar abreviaturas, significados ou códigos desconhecidos;

- As mensagens devem orientar o usuário em relação à tarefa que está sendo executada, comandos que estão sendo processados ou em andamento a ajudar o usuário a resolver problemas;

- As mensagens devem evitar informações ou palavras desnecessárias e informar o estado do sistema, interação do usuário, situação perigosa, falhas, resolução de problemas, etc.

- Oferecer orientações para o usuário em caso de erro.

- Oferecer feedback imediato, ou em caso de processamento, enviar mensagem ao usuário, informando o estado de processamento da informação e seu resultado final (conclusão);

- Feedback de atraso deve ser indicado ao usuário, pois na ausência deste, o 
usuário pode interpretar como erro no sistema ou na tarefa que ele executou;

- Pode ser acompanhado de sinais sonoros que identifiquem a conclusão da tarefa;

\section{CONSIDERAÇÕES FINAIS}

Como foi discutido ao longo deste artigo, apesar da tecnologia ter progredido com o decorrer dos anos e produzido produtos cada vez mais rápidos e seguros, ainda existem dificuldades em relação a usuários idosos na utilização destes meios. Seja em relação ao não acompanhamento dessas mudanças ou pelas limitações cognitivas que ocorrem naturalmente com o processo de envelhecimento, os meios tecnológicos atuais não satisfazem totalmente as necessidades dos usuários idosos, fazendo com que alguns pensem que o problema de não aprendizado é culpa deles e por isso, se tornam dependentes de outras pessoas para ter acesso a diversos serviços.

Em relação aos caixas eletrônicos, por meio da consulta bibliográfica, foi constatado que há dificuldade de operação de usuários idosos em terminais de autoatendimento bancários. Isso porque a dificuldade causa principalmente medo de serem alvos de golpes e a falta de experiência na realização da tarefa causar algum problema como perda de valores, bloqueio de cartão e mesmo o constrangimento em não saber utilizar o sistema. Em face disso, as operações mais utilizadas por esses usuários são o saque e consulta de saldo, pois são consideradas por eles as tarefas mais importantes, e que a consequência da dificuldade de compreensão e utilização da interface faz com que eles não dominem as demais tarefas.

Através das etapas de Exploração Inicial e Processo de descoberta do método do Design Participativo (MORAES E SANTA ROSA, 2012) buscou-se descobrir as necessidades de usuárias idosas relacionadas ao uso do caixa eletrônico e com base nos resultados obtidos, gerar requisitos preliminares para o desenvolvimento de uma proposta de interface para caixas eletrônicos.

Por fim, esta pesquisa sinalizou que há possibilidades de outras pesquisas nas áreas de usabilidade de caixas eletrônicos para idosos, podendo ramificar para sugestões como:

- Continuar a pesquisa com o método do Design Participativo incluíndo a fase de prototipagem;

- Realizar pesquisas de necessidades relacionadas ao indivíduo idoso com o caixa eletrônico com o usuário do gênero masculino, uma vez que esta pesquisa só contou com o gênero feminino.

- Realizar testes de usabilidade das tarefas mais utilizadas nos caixas eletrônicos. 


\section{REFERÊNCIAS}

ALMEIDA, H.; BORIN, E.; ALMEIDA, B.; ALMEIDA, M. A percepção da terceira idade sobre o uso de autoatendimento bancário. POLÊMICA Revista Eletrônica. Rio de Janeiro, 2009. Disponível em:

http://www.mpgo.mp.br/portal/arquivos/2013/04/26/14_21_43_647_A_percep\%C3A 7\%C3\%A3o_da_terceira_idade_sobre_o_uso_de_autoatendimento_banc\%C3\%A1rio.p df. Acesso em 05 mar 2015.

ASSOCIAÇÃO BRASILEIRA DE NORMAS TÉCNICAS. NBR 15250: Acessibilidade em caixa de auto-atendimento bancário.Rio de Janeiro, 200518 p.

BRASIL. Estatuto do idoso: lei federal no 10.741, de 01 de outubro de 2003. Brasília, DF: Secretaria Especial dos Direitos Humanos, 2004.

CAMARANO, A. A. Os Novos Idosos Brasileiros: Muito Além dos 60? - Rio de Janeiro: IPEA, 2004.

DRESCH, L. P. $O$ acesso a serviços financeiros por meio de caixas eletrônicos: uma análise da utilização pelos associados de uma cooperativa de crédito. [Monografia] Universidade Regional do Noroeste do Estado do RS, 2012.

IBGE. Síntese de Indicadores Sociais. Uma análise das condições de vida da população brasileira. 2013. Disponível em:

http://biblioteca.ibge.gov.br/visualizacao/livros/liv66777.pdf Acesso em: 06/05/2015

KASHAR, V. Envelhecimento e perspectivas de inclusão digital. Revista Kairós

Gerontologia, 13(2), INSS 2176-901X, São Paulo, novembro/2010: 131-147.

LAKATOS, E. M. MARCONI, M. de A. Fundamentos de metodologia científica. - 5. Ed. São Paulo: Atlas, 2003.

MAZZONI, A. A. TORRES, E. F. Contribuições para uma atenção adequada às pessoas idosas nos serviços de caixa bancário de auto-atendimento. Ciênc. saúde coletiva. n. 4, v.13, p. 1227-1236, Jul/Ago. 2008

MORAES, A. de; FRISONI, B. C. Ergodesign: produtos e processos. Rio de Janeiro: 2AB, 2001.

MORAES, A. de; SANTA ROSA, J. G. Design participativo, técnicas de inclusão de usuários no processo de ergodesign de interfaces. 1a ed. Rio de Janeiro: Rio Book's 2012. 